Aquaculture International

December 2015, Volume 23, Issue 6, Pages 1387-1400

http://dx.doi.org/10.1007/s10499-015-9891-x

http://archimer.ifremer.fr/doc/00252/36349/

(c) Springer International Publishing Switzerland 2015

\title{
Estimating the economic performance of the EU aquaculture sector
}

\author{
Guillen Jordi ${ }^{1,2}$, Natale Fabrizio ${ }^{3}$, Fernandez Polanco José M. ${ }^{4,}{ }^{*}$
}

${ }^{1}$ Unité d'Economie Maritime, UMR AMURE, IFREMER, Plouzané Cedex, France

2 Institut de Ciències del Mar, CSIC, Barcelona, Spain

${ }^{3}$ Institute for the Protection and Security of the Citizen, Joint Research Centre, European Commission, Ispra, VA, Italy

${ }^{4}$ Dpt. Administración de Empresas, Universidad de Cantabria, Santander, Spain

*Corresponding author : José M. Fernandez Polanco, email address : polancoj@unican.es

\begin{abstract}
:
Despite the growing importance and high priority assigned by the EU policy makers to the development of aquaculture, little attention has been given to analyze the economic performance of the sector at EU level. Recently, the profitability of the EU aquaculture sector has been estimated by the European Commission's Scientific, Technical and Economic Committee for Fisheries (STECF). However, the few studies that have estimated the profitability of the EU aquaculture sector show sometimes divergent results. In this paper, the economic performance of the EU aquaculture sector is analyzed by country, segment and main species for the years 2006, 2009 and 2010 using financial and accounting data extracted from the Amadeus database and results are compared to other studies. This analysis helps to understand the methodological differences between the diverse sources. Moreover, this alternative methodology offers a simpler and faster alternative to the STECF's profitability estimates of the aquaculture sector. The analysis indicates that after the economic downturn, companies started to recover profits in 2010 in almost all segments and countries, and that the highest profitability is recorded by companies in the marine segment as compared to freshwater and shellfish.
\end{abstract}

Keywords : Economic performance, European Union, EBIT, Profit margin, ROI, Profitability 


\section{Introduction}

Aquaculture production by the 27 European Union Member States (EU 27) reached 1.26

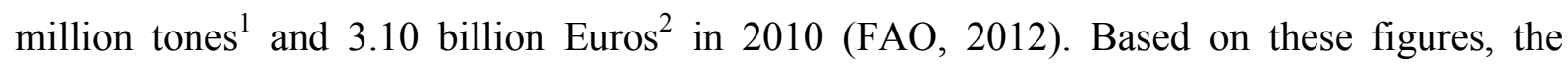
production value of the EU aquaculture sector represents more than half of the EU wild catch fisheries.

The growing importance of aquaculture and its potential to compensate for stagnating (or even declining) fishery supply and support income and employment in coastal and rural areas have been recognized by EU policy. The reform of the Common Fishery Policy aims to boost the growth of the aquaculture sector by setting strategic guidelines, common priorities and exchange of best practice and by giving higher prominence to aquaculture in the proposal for the European Maritime and Fisheries Fund. Given the relevance assigned to the sector by the EU policy there is a higher demand on data and analyses to monitor its economic performance at EU level.

The profitability of the aquaculture sector at EU level has been examined in a study by Ernst \& Young et al. (2008) with reference to 2006 data, in a report by Framian (2009) also with reference to 2006 data and recently by STECF (2012b) with reference to 2008 and 2009 data, and STECF (2013) with reference to 2008, 2009 and 2010 data.

To complement previous analyses this paper uses financial and accounting data extracted from the Amadeus database to estimate the economic performance of the EU aquaculture

\footnotetext{
${ }^{1}$ Annual EU aquaculture production is estimated to be 1.36 million tones in 2010 according to STECF (2013), and 1.30 million tones in 2009 according to EUROSTAT (2013) data. Total EU-27 landings in 2010 from capture fisheries accounted for 5.39 million tones, including 1.03 million tones from inland waters (FAO, 2012). Article 2, of the EC Regulation No 762/2008 of the European Parliament and of the Council of 9 July 2008 on the submission by Member States of statistics on aquaculture and repealing Council Regulation (EC) No 788/96, defines "production" as the output from aquaculture at first sale, including production from hatcheries and nurseries offered for sale. It should be noted that total sales it is then used as an estimate of total production. Even both variables can have a similar evolution over time, they can be different year by year. This happens because companies may decide to keep more or less fish on stock depending on the economic expectations, and because there are long-live species that may take several years to grow. On this last case, production (in weight terms) takes place every year, but the sale may only take place at the last year of the production.

${ }^{2}$ Equivalent to 4.11 billion US\$, using an exchange rate of 1 EUR equal to 1.3257 USD, following European Central Bank exchange rate data. STECF (2013) estimated the EU aquaculture production to be worth 3.58 billion Euros, and Eurostat (2013) 3.22 billion Euros in 2009. EU fisheries turnover (excluding Greece) is estimated to be 6 billion Euros in 2010 (STECF, 2012a).
} 
sector by country and main segment for the years 2006, 2009 and 2010. Results and methodologies of the different studies are compared to obtain a more complete view of the EU aquaculture sector performance.

\section{Materials and Methods}

\subsection{Data}

The main data source used in this study is the Amadeus database managed by Bureau van Dijk (2012). The database covers firm-level accounting data in standardized financial format from 38 European countries. It includes financial information (balance sheet, and profit and loss account), classification according to industry activity codes, legal form, legal status and a brief description of the main lines of activities for almost 9 million of companies. The data is collected mainly from national chamber of commerce registers and public balance declarations.

In the Amadeus database the companies are classified with the three-digit NACE $\operatorname{code}^{3}$ (the European standard of industry classification). The NACE Rev 2 code A.3.2 was used to select the companies having aquaculture as their main economic activity. The last number of the NACE code classifies the companies between marine and freshwater aquaculture (A.3.2.1 stands for marine aquaculture, A.3.2.2 stands for freshwater aquaculture, while A3.2.0 is generically indicating aquaculture ${ }^{4}$ ). The narrative description of area of activity for each company available from the Amadeus database was used to identify companies in the shellfish sector.

\footnotetext{
${ }^{3}$ The Statistical Classification of Economic Activities in the European Community (in French: Nomenclature statistique des activités économiques dans la Communauté européenne), commonly referred to as NACE, is a European industry standard classification system.

${ }^{4} 18$ companies were classified A.3.2.0.
} 
The annual data extracted from the Amadeus database ${ }^{5}$ for the years 2009, 2010 and 2011 were combined with 2006 data from the Ernst \& Young et al. (2008) report, which was also based on the same database.

The 2009 data refer to more than 1,000 companies $(1,024)$ for a total turnover of almost 2.5 billion Euros, which represents $75 \%$ of the total EU-27 aquaculture sector turnover in 2009 (based on STECF report 2012b) ${ }^{6}$. For more than 800 companies (802) data were available for both 2009 and 2010, and representing 67\% of all EU-27 aquaculture sector turnover. For a smaller group of companies data were available for several years ${ }^{\text {ee }}$ combinations from 2006 to 2011. Table 1 gives a summary of the data used in this study. Data were classified by single years $\left(2006,2009,2010\right.$ and 2011) and years ${ }^{e e}$ combinations for which data were available for the same companies.

Table 1 to be placed around here

\subsection{Methodology}

The main variables extracted from the Amadeus database were turnover, EBIT and number of employed persons.

The turnover comprises all market sales of goods and services supplied to third parties (EC, 1998). The EBIT (EBIT, Earnings Before Interest and Taxes) or operating profit is a measure of a firm's profitability that excludes interest and income tax expenses, and is calculated by subtracting the operating expenses from the operating revenues.

In Framian (2009) and the Economic Performance of the EU Aquaculture Sector reports (STECF, 2012b and 2013), EBIT was calculated, according to the Structural Business Statistics definitions (EC, 1998).

\footnotetext{
${ }^{5}$ For 2011 data was only available for a reduced number of companies at this time stage.

${ }^{6}$ Other approaches to measure the representativeness of the panel are not so favorable, such as the number of companies since STECF $(2012,2013)$ estimate between 14 and 15 thousand the number of aquaculture companies in the EU.
} 
The difference in the EBIT estimation is because the Amadeus data base follows a firm financial-accounting perspective $\left(\right.$ EBIT $\left._{\mathrm{FIN}}\right)$, while the STECF reports follow a more economic perspective $\left(\mathrm{EBIT}_{\mathrm{ECO}}\right)$, as it aims to know strictly the aquaculture sector's economic performance (EC, 1998; STECF, 2011).

$\mathrm{EBIT}_{\mathrm{ECO}}=$ Turnover + Other Income + Subsidies - Energy costs - Wages and salaries Imputed value of unpaid labor - Livestock costs - Feed costs - Repair and maintenance Other Operational costs - Depreciation of capital.

It should be noted that the Amadeus data base does not take into account the imputed value of unpaid labor, but considers the extraordinary costs.

$\mathrm{EBIT}_{\mathrm{FIN}}=$ Turnover + Other Income + Subsidies - Energy costs - Wages and salaries -

Livestock costs - Feed costs - Repair and maintenance - Other Operational costs Extraordinary costs - Depreciation of capital.

The EBIT to turnover ratio (commonly referred as EBIT ratio or EBIT margin) gives an assessment of the profitability by comparing the earnings with the revenues and is indicating the percentage of the remaining revenues (earnings) after the operating expenses.

$$
\text { EBIT to turnover ratio }=\text { EBIT } / \text { Turnover }
$$

Following previous distinction between $\mathrm{EBIT}_{\mathrm{FIN}}$ and $\mathrm{EBIT}_{\mathrm{ECO}}$, same distinction is applied to the EBIT to turnover ratio.

Moreover, STECF (2012b, 2013), among other economic performance indicators, also estimates the Return On Investment (ROI). ROI also provides a snapshot of profitability, in this case, adjusted for the size of the investment assets tied up in the firm.

Return On Investment $(\mathrm{ROI})=$ EBIT / Total Value of Assets

\section{Results}

\subsection{Overview of the EU aquaculture sector}


The EU (27) represents $1.6 \%$ of the world aquaculture production in weight and $3.3 \%$ in value. The EU (27) contribution to world aquaculture production has been decreasing significantly over time.

Spain, with $20 \%$ of the total EU production in weight, is the largest aquaculture producer in the EU, followed by France (18\%), United Kingdom (16\%), Italy (12\%) and Greece (9\%). In terms of value, France is the largest EU producer with $21 \%$ of the total EU aquaculture, followed by the United Kingdom (19\%), Spain (13\%), Greece (12\%) and Italy (11\%). These five countries account for $75 \%$ of the total EU aquaculture production in weight and $76 \%$ in value, as can be seen on figure 1.

\section{Figure 1 to be placed around here}

The main species produced by the EU aquaculture sector are mussels (blue and Mediterranean mussels), rainbow trout, Atlantic salmon, oysters, gilthead sea bream, common carp and European sea bass (EUROSTAT, 2012; FAO, 2012). These species constituted more than $90 \%$ in weight and more than $85 \%$ in value of the total EU aquaculture production for 2010.

The STECF (2013) report estimates the value of aquaculture sales to be $95 \%$ of the total income, $3 \%$ comes from other income and $2 \%$ from direct subsidies.

In 2010, the shellfish segment accounted for 0.63 million tones and 0.91 billion Euros, the marine segment for 0.35 million tones and 1.43 billion Euros, and the freshwater segment for 0.28 million tones and 0.76 billion Euros (FAO, 2012) ${ }^{7}$.

On the basis of the STECF report (STECF, 2013) the most important costs of the EU shellfish aquaculture sector are related to labor (wages and salaries (19\%) and imputed value of unpaid labor $(19 \%))$ and livestock costs $(28 \%)$, as can be seen on figure 2 . A large part of the employment is not performed under a formal contract, because most workers are either the owners of the company or family members, with an important presence of part-time

\footnotetext{
${ }^{7}$ STECF (2013) estimates that in 2010 the total sales (production) of the EU (27) shellfish aquaculture were 0.72 million tones and 1.12 billion Euros, of the marine aquaculture were 0.51 million tones and 1.57 billion Euros, and of the freshwater aquaculture were 0.31 million tones and 0.91 billion Euros.
} 
employment. The most important costs of the EU marine aquaculture sector are the feed costs (26\%), followed by other operational costs $(23 \%)$, livestock costs $(18 \%)$ and wages and salaries $(18 \%)$. It is important to notice the null importance of imputed value of unpaid labor in the marine aquaculture, because most of the work is done under formal contracts. The most important costs of the EU freshwater aquaculture sector are the feed costs $(37 \%)$, followed by wages and salaries $(19 \%)$ and livestock costs $(15 \%)$. There is an important level of part-time employment in the freshwater aquaculture sector, on the other hand, unpaid labor is of low importance.

\section{Figure 2 to be placed around here}

\subsection{Profitability analysis based on the Amadeus database}

The overall profitability of the EU aquaculture sector based on the EU companies with aquaculture as main activity available at the Amadeus database, measured by the EBIT ratio, was estimated to be $10.9 \%$ in $2006,4.3 \%$ in $2009,7.4 \%$ in 2010 , and $8.1 \%$ in $2011^{8}$.

\section{Table 2 to be placed around here}

From table 2 it can be seen that 2009 was a negative year for the EU aquaculture sector since the profitability (EBIT ratio) was the lowest.

This observation is confirmed by the profitability trend for companies where data is available for multiple years. In all groups the economic performance was lower in 2009 in respect of 2006, 2010 and 2011. The results indicate that after the economic downturn in 2008-2009, profits increased in 2010 and 2011. Indeed, the business volume (turnover) increased by more than $11.2 \%$ between 2009 and 2010; while for the period 2006-9 the growth was of $4.4 \%$ per year.

\footnotetext{
${ }^{8}$ Given the low number of companies for which data was available conclusions for 2011 have to be taken with caution.
} 


\section{Profitability by country}

Table 3 shows the overall profitability of the aquaculture companies from the Amadeus database by country and year. This gives the possibility to understand which countries have recovered from the 2009 downturn.

\section{Table 3 to be placed around here}

From table 3 it can be observed that for countries with a relatively high number of companies, the profitability of the aquaculture sector diverges slightly from the overall profitability (EBIT ratio of $4.3 \%$ ). While most countries have profitability between 4 and $10 \%$, South-Western countries presented worst results (Portugal -3.2\%, Spain -1.7\% and France 0.5\%).

It can also be seen that overall profitability increased in Portugal, Spain and France while worsened in Czech Republic, Greece, Hungary, and Italy.

Overall turnover from the aquaculture sector has increased by $11.2 \%$ from 2009 to 2010 . While the turnover from the aquaculture sector in most EU countries has increased, for the Netherlands, Romania, Slovakia and Sweden it has significantly decreased.

\section{Profitability by segment}

The profitability of the EU aquaculture by marine and freshwater environment was analyzed looking at the NACE classification available from the Amadeus database while the companies involved in shellfish aquaculture were identified looking at the narrative description of the main business area of the company. This information was available only for a limited number of companies.

In 2006 there were 76 companies listed as shellfish producers, for a total of 6 countries and 112 million Euros of turnover. For all these companies data was available for 2006 and 2009 while for only 55 of them data was available also for 2010 as can be seen from table 4 . 
The profitability by segment shows the same temporal evolution as the overall profitability with lower values in 2009 in respect of 2006 and 2010. In all years marine aquaculture has a higher profitability than freshwater and shellfish aquaculture.

The shellfish sector that appears in this analysis may not be representative of the shellfish gathering microenterprises common in Southern Europe, but more similar to the larger German, Dutch, Danish or Irish companies, because data available in the Amadeus database are from medium and large companies. On the other hand, due to statistical confidentiality or willingness to participate, data from large companies could be missing on the STECF estimations.

\subsection{Comparison with other sources}

The profitability of the aquaculture sector at EU level has been examined in a study by Ernst \& Young et al. (2008) with reference to 2006 data, in a report by Framian (2009) also with reference to 2006 data and recently by STECF (2012b) with reference to 2008 and 2009 data, and STECF (2013) with reference to 2008, 2009 and 2010 data.

Ernst \& Young et al. (2008) analyzed the composition and competitiveness of the EU aquaculture sector. The report provides in its annex turnover and EBIT ratio data from the Amadeus database for the 510 companies with the largest sales value in 2006. Assembling these data it can be estimated that the EBIT $_{\text {FIN }}$ ratio of the EU aquaculture sector was $10.9 \%$ in 2006.

Framian (2009) carried out a pilot survey compiling data mostly for the year 2006 in sixteen EU Member States ${ }^{9}$. The study covered 55 segments that produced 1.2 million tons of fish with an estimated value of 3.5 billion Euros, representing more than $90 \%$ of the EU

\footnotetext{
${ }^{9}$ Czech Republic, Denmark, Finland, France, Germany, Greece, Hungary, Ireland, Italy, Lithuania, Netherlands, Poland, Portugal, Spain, Sweden and United Kingdom.
} 
aquaculture production in terms of volume in $2006^{10}$. Assembling the data provided in the report, it can be estimated that the $\mathrm{EBIT}_{\mathrm{ECO}}$ ratio of the EU aquaculture sector was $12.6 \%$ in 2006. Compared to Ernst \& Young et al. (2008) study, Framian (2009) does not consider the extraordinary costs, but considers the imputed value of unpaid labor as a cost. When not accounting for the imputed value of unpaid labor, the estimated EBIT ratio in the Framian report was $14.7 \%$.

On the other hand, STECF (2012b) reported the profitability based on the Return on Investment (ROI) of the EU aquaculture sector in $-3.1 \%$ for 2008 and $-1.6 \%$ for 2009 . While the STECF (2013) estimated the ROI for 2010 to be 5.7\%. The estimated profitability in the STECF (2012b and 2013) reports rather depends on the data availability by country. On the STECF (2013) report, data are not available for Austria, Belgium, Czech Republic, Hungary, Latvia, Lithuania, Luxemburg and Slovakia, because reporting of freshwater aquaculture is not compulsory under the Data Collection Framework (DCF) data collection and most of their aquaculture production is freshwater based. Greece did not report any data for this report, while Italy reported only partial data and so it was excluded from the analysis. Germany, Poland and Slovenia reported marine water aquaculture data, but not freshwater aquaculture. The Netherlands did not provide 2010 data, but 2008 and 2009 data. Moreover, the reported data still contain some missing variables and data quality issues. Hence, it is relevant to check the coherence of the STECFees profitability estimates, especially for certain countries. Assembling the data available from the STECF report (2013), it can be estimated that the EBIT $_{\mathrm{ECO}}$ was $-0.9 \%$ and the $\mathrm{EBIT}_{\mathrm{FIN}}$ was $5.0 \%$ in $2008^{11}$, the $\mathrm{EBIT}_{\mathrm{ECO}}$ was $-6.6 \%$ and the

\footnotetext{
${ }^{10}$ The EU aquaculture production in terms of volume amounted to 1.3 million tons in 2006 according to FAO and Eurostat.

${ }^{11}$ Available full data from Bulgaria, Cyprus, Denmark, Estonia, Finland, Ireland, Malta, Netherlands, Spain and Sweden, and for Germany and Slovenia only available marine aquaculture data.
} 
EBIT $_{\mathrm{FIN}}$ was $-3.0 \%$ in $2009^{12}$, and the $\mathrm{EBIT}_{\mathrm{ECO}}$ was $10.1 \%$ and the $\mathrm{EBIT}_{\mathrm{FIN}}$ was $18.4 \%$ in $2010^{13}$

Table 5 compares the profitability based on the EBIT ratio of the EU aquaculture sector estimated by the different sources: Amadeus database in Ernst \& Young et al. (2008) and in this study, Framian (2009) and the STECF (2013) report.

\section{Table 5 to be placed around here}

Results from table 5 confirm the improvement in the economic performance of the EU aquaculture sector after years 2008-2009, especially according to STECF (2013) where the profitability for these initial years was even lower.

Table 6 compares the profitability based on the EBIT ratio of the EU aquaculture subsectors (marine, freshwater and shellfish) estimated by the different sources.

\section{Table 6 to be placed around here}

Results from table 6 show that marine aquaculture was the only subsector obtaining negative profits in 2008 and 2009, and thus worsening the overall EU aquaculture sector profitability.

\section{Discussion}

The EU contribution to world aquaculture production is rather small and has been decreasing over time. But on the basis of Framian (2009) and STECF (2012b and 2013), it can be concluded that the value of the EU aquaculture production is slightly higher than the value estimated by Eurostat and FAO. This is mainly because Eurostat and FAO consider only the aquaculture production for human consumption. Indeed, STECF (2013) estimated the GVA of the EU aquaculture sector in 2010 to be about 1.5 billion Euros, compared to 3.4 billion Euros of the EU fishing sector (STECF 2012a).

\footnotetext{
${ }^{12}$ Available full data from Bulgaria, Cyprus, Denmark, Estonia, Finland, Ireland, Malta, Netherlands, Portugal, Romania, Spain and Sweden, and for Germany, Poland and Slovenia only available marine aquaculture data.

${ }_{13}$ Available full data from Bulgaria, Cyprus, Denmark, Estonia, Finland, France, Ireland, Malta, Portugal, Romania, Spain and Sweden, and for Germany, Poland and Slovenia only available marine aquaculture data.
} 
Despite the importance of the EU aquaculture sector, its economic performance is rather uncertain compared to other EU economic sectors (Asche, 2008; Bergfjord, 2009; Sgroi et al., 2014). Results from this study offer a positive outlook on the economic performance of the EU aquaculture sector which appears to recover profitability after the 2009 crises, confirming STECF (2013) trends. But, there are important discrepancies between the economic performance figures from this study and the STECF reports (STECF, 2012b and 2013). The main reasons for the existence of these divergences could be attributed to:

- different treatment in the two sources for "imputed value of unpaid labor" and "extraordinary costs/income";

- the fact this study is based on panel data from 1,024 mostly medium and large size companies rather than on a statistical sampling including part time and small companies;

- the fact that economic accounts in the Amadeus database does not allow a separation of the area of business related to aquaculture production (main activity) from other activities within the same company.

STECF reports (STECF, 2012b and 2013) included the "imputed value of unpaid labor" as a cost, but not the "extraordinary costs/income". This can partially explain the lower profitability (EBIT $\mathrm{ECO}_{\mathrm{E}}$ margin) on the STECF report where imputed value of unpaid labor was considered as a cost. This difference can be significant in those segments that are mostly run by sole or family units and are very labor intensive, such a shellfish gathering (see figure 2 ). By subtracting the "imputed value of unpaid labor" and adding the "extraordinary costs/income" on the $\mathrm{STECF}^{\text {ee }}$ EBIT $\mathrm{ECO}_{\mathrm{EO}}$ it can be obtained the $\mathrm{EBIT}_{\mathrm{FIN}}$, and consequently the EBIT $_{\mathrm{FIN}}$ margin, in order to harmonize the STECF profitability indicator with the one estimated from the Amadeus data. 
The companies from the Amadeus panel are medium and large size companies; while the STECF data is collected by statistical sampling including part time and small companies. On average, the companies from the Amadeus database have a higher turnover than the ones from the STECF database (STECF, 2012b and 2013). Thus, this study, by considering the Amadeus selected panel of companies, has lower statistical representativeness in respect of the more rigorous and comprehensive data collection under the EU Data Collection Framework (DCF). In particular small companies and specifically the shellfish sector may be underrepresented. Despite this limitation the panel has an overall high coverage in terms of turnover $(75 \%)$ and includes also freshwater aquaculture. The availability of data for individual companies over time also provides the unique opportunity of examining the performance trend during last years. Moreover, sometimes data from large companies cannot be reported inside the STECF statistics due to confidentiality issues or companies not willing to collaborate.

Therefore, the consideration of data from the Amadeus panel while representing a large share of the EU aquaculture turnover ${ }^{14}$ could represent a bias if profitability is shown to be dependent (affected) from the turnover. There could be some economies of scale so that the largest companies, with highest turnover could exploit and obtain larger profits. To check for the presence of this potential bias in Figure 3 the profitability is plotted against the turnover. The figure shows that there is a higher variability on the profitability for smaller companies with smaller turnover. The almost flat trend line and its very small $\mathrm{R}^{2}$ indicate that there is no significant relation between profitability and turnover for the EU aquaculture (large and medium) companies. On the basis of this observation it can be concluded that the panel data used in the analysis should not suffer of a bias linked to an overrepresentation of large companies.

\footnotetext{
${ }^{14}$ Data from the smallest companies present problems due to the lack of certain parameters or their very low scale.
} 


\section{Figure 3 around here}

However, it should be analyzed if this stands for individual companies (e.g., shellfish gathering) that may have a very different cost structure (e.g., with null or low capital costs and investments).

The turnover of the Amadeus selected companies in many cases exceeds the value of production reported in FAO statistics for specific segments and countries. This indicates that a relevant proportion of the turnover of the examined companies is generated from other activities than their main activity of domestic aquaculture production, such as production of juveniles, production of feedstuff, fishing activities, marketing, processing and production in foreign countries.

The profitability of the aquaculture sector is, in general terms, similar to other food production sectors, even if it can suffer from bad periods on a cyclic way. Nikolik (2011) reported the average 2005-2010 EBITDA (Earnings Before Interest, Taxes, Depreciation and Amortization) margin to be more than $16 \%$ for salmon farmers, around $15 \%$ for seabass and seabream farmers, more than $14 \%$ for wild catch fisheries, more than $10 \%$ for poultry, more than $8 \%$ for seafood processing, almost $7 \%$ for processed meat, and almost $7 \%$ for red meat. However, the profitability of the aquaculture sector is reduced when capital costs are considered (i.e., depreciation and amortization) because aquaculture is often a capital intensive business (e.g., depreciation to be between 6 and $13 \%$ of the production costs according to STECF (2013), while Bjorndal and Guillen (2014) estimated depreciation to e $12.9 \%$ for the sole culture).

\section{Conclusions}

The findings of this study by using Amadeus data show that in 2010-11 there is an improvement in the economic performance of the EU aquaculture sector from the beginning 
of the economic crisis (2008-2009). These trends confirm the results of STECF (2012b and 2013); however, the figures do not exactly match. Given this variability on the exact figures, economic performance results should be considered with caution.

Despite the global expansion of aquaculture, and the mild positive signs in terms of economic performance emerging from this study the future of the sector in the EU remains uncertain. The successful development of the EU aquaculture sector implies control of the biological production processes, together with economic sustainability, in other words, a profitable production over time. The EU aquaculture sector has to face a fierce foreign competition that brings market prices down, high labor and capital costs and administrative burdens that slow down investments in the sector, hindering the full potential of the EU aquaculture sector (STECF, 2013).

The findings of this study by using Amadeus data while not meant to substitute the annual economic performance assessment for the EU aquaculture by the STECF represent a useful point of reference and complement especially in a phase of initial implementation of the EU Data Collection Framework for aquaculture. Indeed, data coverage and quality from the annual STECF aquaculture reports is likely to improve in the future as data collection for this sector becomes more established. A problem which is not going to be easily addressed is the lack of coverage for the freshwater sector since according to existing legislation the submission of such data by the MSs is only on a voluntary basis.

While not being statistically representative, one advantage from using the Amadeus database is in the availability of individual companies ${ }^{\text {ee }}$ data, which allows tracking performance of a selected panel over time. Moreover, Amadeus data are made available earlier than the STECF. The fact that the Amadeus database contains data from companies, it informs on the robustness and sustainability of the companies involved in the aquaculture sector; while STECF analyses the economic performance obtained from the aquaculture activity. 
Another advantage is that, on average, Amadeus data are available between 6 months and one year after the end of the year; while STECF is available for most countries after more than a year and a half of the end of the year. Complementing statistical surveys with public individual companies accounts could help STECF data collection to target those segments where more data is necessary (i.e. those segments that present higher changes from previous year). This should lead in the long-run to have more stable and robust estimates of the EU aquaculture economic performance and to better monitor the evolution and growth of the sector also in response of the measures envisaged by the new Common Fishery Policy.

\section{References}

Asche, F. (2008). Farming the sea. Marine Resource Economics, 23(4): 527.

Bergfjord, O. J. (2009). Risk perception and risk management in Norwegian aquaculture. Journal of Risk Research, 12(1): 91-104.

Bjørndal, T., \& Guillen, J. (2014) The future of sole farming in Europe: cost of production and markets. Aquaculture Europe, 39(2): 5-13.

Bureau Van Dijk (2012) Amadeus A database of comparable financial information for public and private companies across Europe. http://www.bvdinfo.com (accessed April 2012).

Ernst \& Young, AND-I, Eurofish, \& Indemar (2008) Etude des performances économiques et

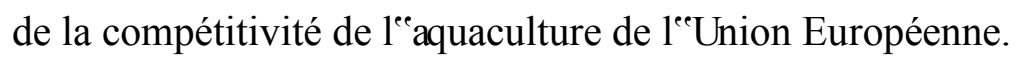

European Commission (1998) Commission Regulation (EC) No 2700/98 of the 17 December 1998 concerning the definitions of characteristics for structural business statistics. Official Journal of the European Union.

European Commission (2008) Commission Regulation (EC) No 762/2008 of the European Parliament and of the Council of 9 July 2008 on the submission by Member States of statistics 
on aquaculture and repealing Council Regulation (EC) No 788/96. Official Journal of the European Union.

EUROSTAT (2013) Aquaculture production, Total. Consultation on April 2013. http://epp.eurostat.ec.europa.eu/portal/fisheries/data/main_tables

FAO (2012) Global Aquaculture Production 1950-2009 database (Release date: March 2012). Electronic address: $\quad$ http://www.fao.org/fishery/statistics/global-aquacultureproduction/query/en

FRAMIAN (2009) Review of the EU aquaculture sector and results of costs and earnings survey, part 1 of the final report on definition of data collection needs for aquaculture, Ref. No, FISH/2006/15-Lot 6.

Nikolik, G. (2011) A banker's view on the dynamics, challenges and investment flows in the aquaculture industry. Global Outlook for Aquaculture Leadership. November 2011. Santiago, Chile. Available at: http://www.gaalliance.org/update/GOAL11/Nikolik.pdf.

Sgroi, F., Tudisca, S., Di Trapani, A. M., \& Testa, R. (2014). Economic evaluation of aquaculture investments under conditions of risk and uncertainty in the Mediterranean Sea. American Journal of Applied Sciences, 11: 1727-1734.

STECF (2011) Methodologies for 2011 economic reports. Publications Office of the European Union. Luxembourg. 59 pp.

STECF (2012a) The Annual Economic Report on the EU fishing fleet. Publications Office of the European Union. Luxemburg. 233 pp.

STECF (2012b) Economic Performance of the EU Aquaculture Sector. Publications Office of the European Union. Luxemburg. 337 pp.

STECF (2013) 2012 Economic Performance of the EU Aquaculture Sector. Luxembourg. Publications Office of the European Union. 238 pp. 
Table 1: Number of companies, turnover and EBIT available by year (Source: Amadeus database)

\begin{tabular}{|c|c|c|c|}
\hline Years & N. Companies & $\begin{array}{l}\text { Turnover (thousand } \\
€)\end{array}$ & EBIT (thousand $€$ ) \\
\hline 2006 & 510 & $1,738,826$ & 189,675 \\
\hline 2009 & 1024 & $2,495,624$ & 106,318 \\
\hline 2010 & 996 & $2,513,175$ & 186,485 \\
\hline 2011 & 64 & 64,548 & 5,245 \\
\hline $2006 \&$ & 295 & $1,205,982$ & 139,042 \\
\hline 2009 & & $1,365,321$ & 65,526 \\
\hline $2009 \&$ & 802 & $2,223,027$ & 109,001 \\
\hline 2010 & & $2,472,491$ & 185,331 \\
\hline $2009 \&$ & 63 & 52,203 & 2,798 \\
\hline 2011 & & 125,357 & 9,99 \\
\hline 2006 & 239 & $1,129,880$ & 134,638 \\
\hline $2009 \&$ & & $1,285,305$ & 65,661 \\
\hline 2010 & & $1,444,959$ & 98,043 \\
\hline 2006 & 29 & 27,484 & 2,088 \\
\hline $2009 \&$ & & 30,098 & 2,133 \\
\hline 2011 & & 39,352 & 3,307 \\
\hline
\end{tabular}




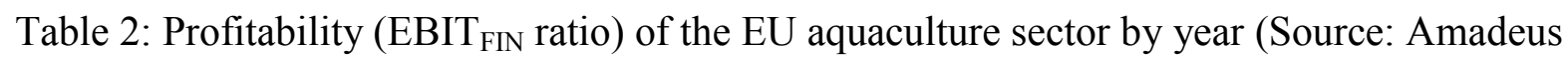
database)
Years
N. companies
EBIT ratio (\%)

2006

510

10.9

\begin{tabular}{lll}
\hline 2009 & 4.3
\end{tabular}

2010

996

7.4

\section{1}

64

8.1

$2006 \& 2009$

$295 \quad 11.5 \& 4.8$

2009 \& 2010

802

$4.9 \& 7.5$

$2009 \& 2011$

$63 \quad 5.4 \& 8.0$

2006, $2009 \& 2010$

$23911.9,5.1 \& 6.8$

2006, 2009 \& 2011

$29 \quad 7.6,7.1 \& 8.4$ 
Table 3: Profitability (EBIT FIN ratio) of the EU aquaculture sector by country for 2009 and 2010. In brackets the profitability for 2009 based on the 1029 companies (Source: Amadeus database).

\begin{tabular}{|c|c|c|c|c|c|c|c|}
\hline \multirow[b]{3}{*}{ Country } & \multicolumn{3}{|c|}{2009} & & \multicolumn{3}{|c|}{2010} \\
\hline & Turnover & EBIT & EBIT margin & & Turnover & EBIT & EBIT margin \\
\hline & $(, 000 €)$ & $(, 000 €)$ & $(\%)$ & N. companies & $(, 000 €)$ & $(, 000 €)$ & $(\%)$ \\
\hline Bulgaria & 2,624 & 290 & $11.0(11.0)$ & 6 & 4,003 & 1,150 & 28.7 \\
\hline Cyprus & 17,561 & 1,308 & $7.4(7.4)$ & 2 & 18,960 & 1,235 & 6.5 \\
\hline Czech Republic & 46,241 & 3,082 & $6.7(7.2)$ & 20 & 47,820 & 2,259 & 4.7 \\
\hline Denmark & 55,202 & 7,093 & $12.8(12.8)$ & 4 & 64,815 & 24,128 & 37.2 \\
\hline Estonia & 988 & 115 & $11.7(6.0)$ & 8 & 1,222 & 17 & 1.4 \\
\hline Finland & 13,679 & 1,392 & $10.2(9.1)$ & 14 & 15,881 & 2,625 & 16.5 \\
\hline France & 168,298 & 2,651 & $1.6(0.5)$ & 141 & 177,438 & 5,673 & 3.2 \\
\hline UK & 528,076 & 52,604 & $10.0(9.7)$ & 15 & 614,427 & 116,765 & 19.0 \\
\hline Greece & 704,610 & 32,058 & $4.5(4.4)$ & 76 & 808,643 & 8,014 & 1.0 \\
\hline Hungary & 27,921 & 2,455 & $8.8(8.6)$ & 31 & 29,967 & 1,847 & 6.2 \\
\hline Italy & 167,702 & 4,823 & $2.9(1.6)$ & 80 & 196,437 & 3,738 & 1.9 \\
\hline Latvia & 745 & 745 & $100.0(100.0)$ & 2 & 734 & 734 & 100.0 \\
\hline Lithuania & 1,131 & 210 & $18.6(18.6)$ & 2 & 1,183 & 330 & 27.9 \\
\hline Netherlands & 45,844 & $-2,394$ & $-5.2(-1.3)$ & 1 & 34,880 & -314 & -0.9 \\
\hline Poland & 3,529 & 419 & $11.9(10.5)$ & 2 & 3,797 & 215 & 5.7 \\
\hline Portugal & 17,857 & $-1,275$ & $-7.1(-3.2)$ & 28 & 35,518 & 3,716 & 10.5 \\
\hline Romania & 99,854 & 4,948 & $5.0(5.2)$ & 217 & 50,463 & 2,862 & 5.7 \\
\hline
\end{tabular}




\begin{tabular}{lrrrrrrr}
\hline Slovakia & 10,709 & -204 & $-1.9(-1.3)$ & 4 & 6,370 & -205 & -3.2 \\
\hline Slovenia & 1,197 & 25 & $2.1(2.1)$ & 1 & 1,347 & 105 & 7.8 \\
\hline Spain & 290,007 & $-2,838$ & $-1.0(-1.7)$ & 117 & 341,587 & 9,266 & 2.7 \\
\hline Sweden & 19,252 & 1,497 & $7.8(7.9)$ & 31 & 16,997 & 1,171 & 6.9 \\
\hline Total & $2,223,027$ & 109,002 & $4.9(4.3)$ & 802 & $2,472,491$ & 185,331 & 7.5 \\
\hline
\end{tabular}


Table 4: Profitability (EBIT FIN ratio) of the EU aquaculture sector by environment (Source: Amadeus database)

\begin{tabular}{lrrrr} 
& N. companies & 2006 & 2009 & 2010 \\
\hline Marine & 111 & 12.9 & 5.2 & 7.0 \\
\hline Freshwater & 67 & 10.2 & 4.8 & 6.5 \\
& 55 & 4.5 & 3.2 & 3.3 \\
\hline Shellfish & 238 & 11.9 & 5.1 & 6.8
\end{tabular}


Table 5: Profitability (EBIT ratio) of the EU aquaculture sector by source

\begin{tabular}{llccccc} 
& & 2006 & 2008 & 2009 & 2010 & 2011 \\
\hline Amadeus database & EBIT $_{\mathrm{FIN}}$ & 10.9 & & 4.3 & 7.4 & 8.1 \\
\hline Framian (2009) & EBIT $_{\mathrm{ECO}}$ & 12.6 & & & & \\
\hline & & & & & & \\
\hline Framian (2009) & EBIT $_{\mathrm{FIN}}{ }^{*}$ & 14.7 & & & & \\
\hline STECF (2013) & EBIT $_{\mathrm{ECO}}$ & & -0.9 & -6.6 & 10.1 & \\
\hline STECF (2013) & EBIT $_{\mathrm{FIN}}$ & & 5.0 & -3.0 & 18.4
\end{tabular}

* Even if it properly does not consider the imputed value of unpaid labor as a cost, the extraordinary costs that should be considered are not considered because of the lack of this data. 
Table 6: Profitability (EBIT ratio) of the EU aquaculture sector by subsector

\begin{tabular}{|c|c|c|c|c|c|c|}
\hline & & & 2006 & 2008 & 2009 & 2010 \\
\hline \multirow[t]{3}{*}{ Marine } & Amadeus database & $\mathrm{EBIT}_{\mathrm{FIN}}$ & 12.9 & & 5.2 & 7.0 \\
\hline & STECF (2013) & $\mathrm{EBIT}_{\mathrm{FIN}}$ & & -3.3 & -32.7 & 1.4 \\
\hline & STECF (2013) & $\mathrm{EBIT}_{\mathrm{ECO}}$ & & -1.0 & -33.0 & 1.6 \\
\hline \multirow[t]{3}{*}{ Freshwater } & Amadeus database & $\mathrm{EBIT}_{\mathrm{FIN}}$ & 10.2 & & 4.8 & 6.5 \\
\hline & STECF (2013) & $\mathrm{EBIT}_{\mathrm{FIN}}$ & & 4.9 & 9.8 & 7.3 \\
\hline & STECF (2013) & $\mathrm{EBIT}_{\mathrm{ECO}}$ & & 4.3 & 7.6 & 5.2 \\
\hline \multirow[t]{3}{*}{ Shellfish } & Amadeus database & $\mathrm{EBIT}_{\mathrm{FIN}}$ & 4.5 & & 3.2 & 3.3 \\
\hline & STECF (2013) & $\mathrm{EBIT}_{\mathrm{FIN}}$ & & 29.2 & 34.5 & 40.2 \\
\hline & STECF (2013) & $\mathrm{EBIT}_{\mathrm{ECO}}$ & & 3.2 & 22.8 & 23.3 \\
\hline
\end{tabular}


Figure 1: Aquaculture production in EU 27 per country in weight and value in 2010 (Source:

FAO, 2012)
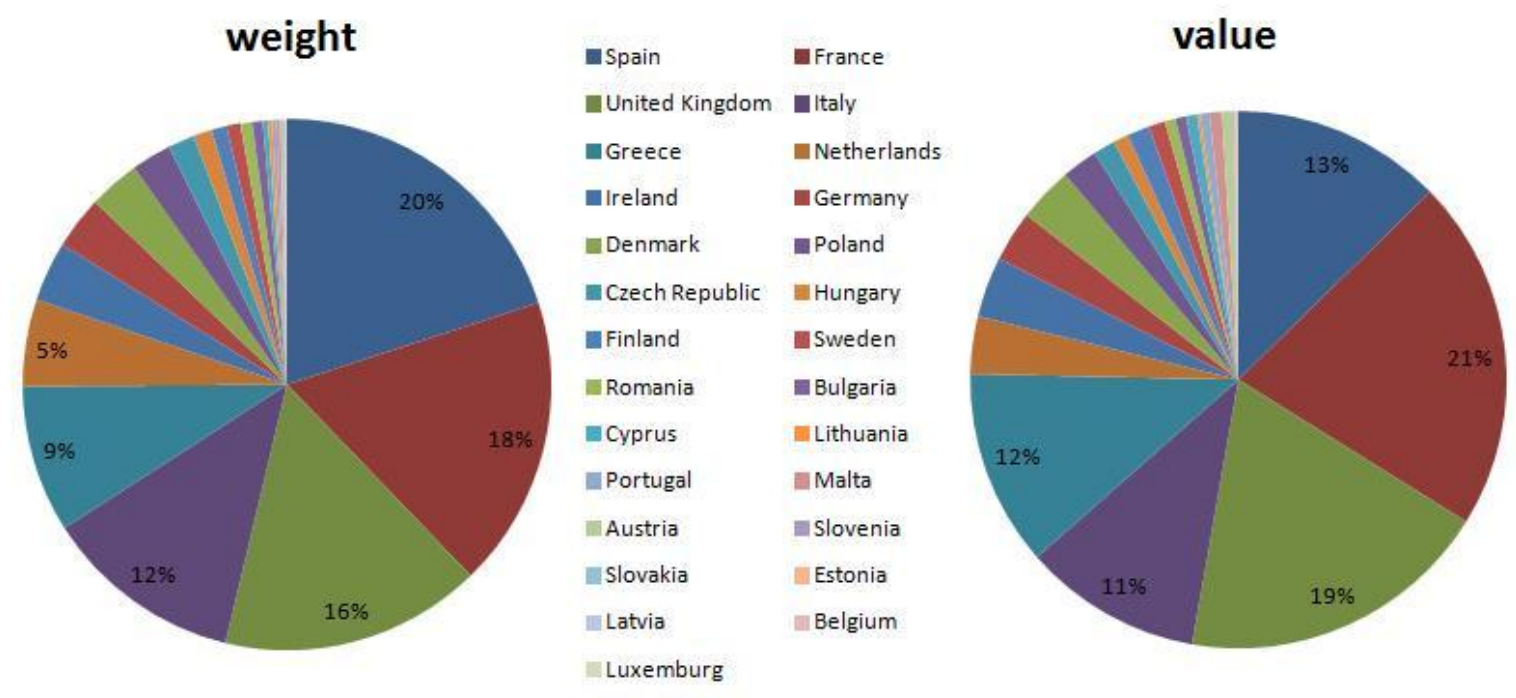
Figure 2: Cost breakdown by aquaculture subsector (shellfish, marine and freshwater) in 2010 (Source: STECF, 2013)
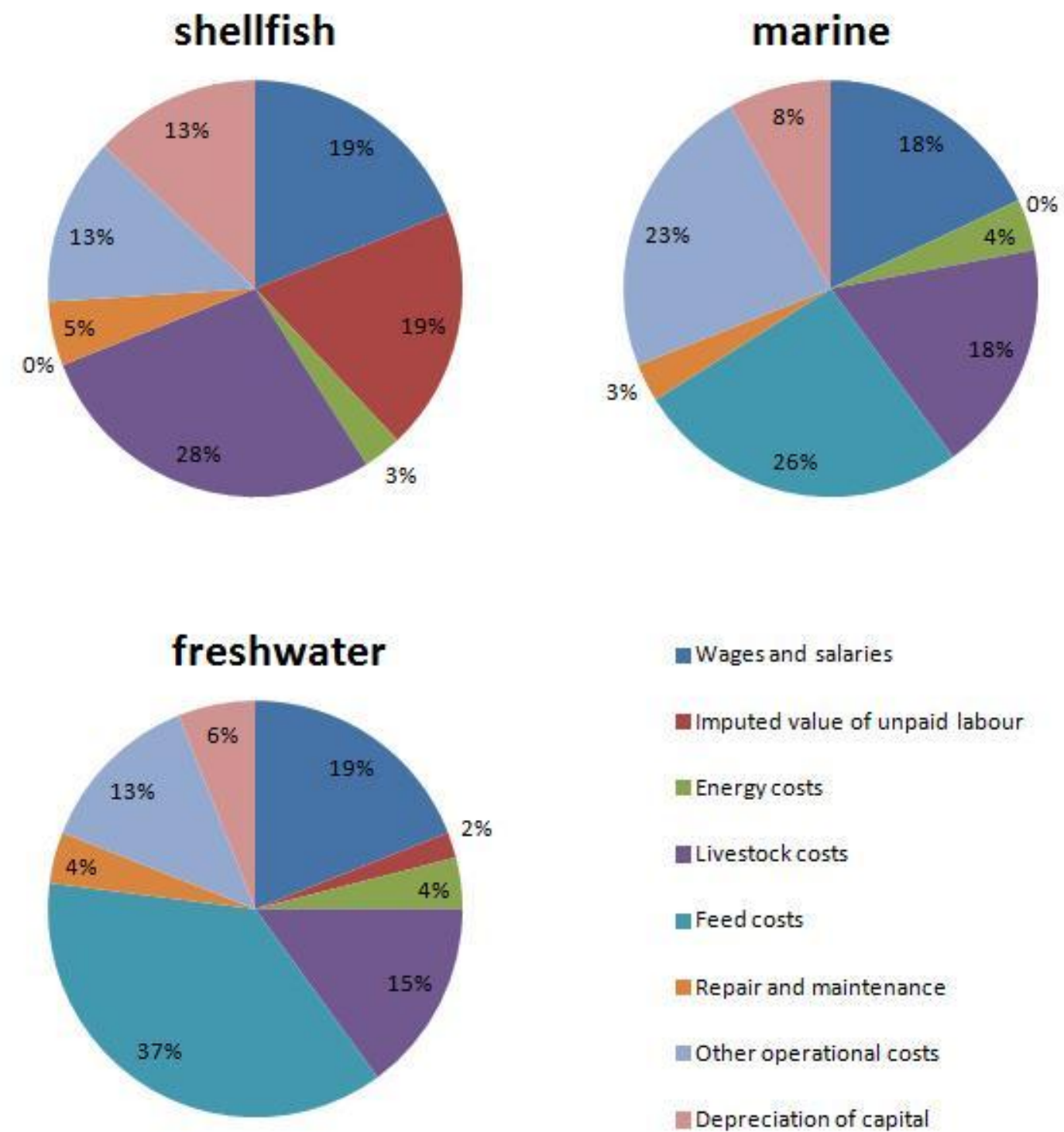

Wages and salaries

- Imputed value of unpaid labour

Energy costs

Eivestock costs

Feed costs

Repair and maintenance

wether operational costs

Depreciation of capital 
Figure 3: Relation between profitability and turnover of the EU aquaculture companies for 2009; $x$-axis turnover and y-axis EBIT ratio

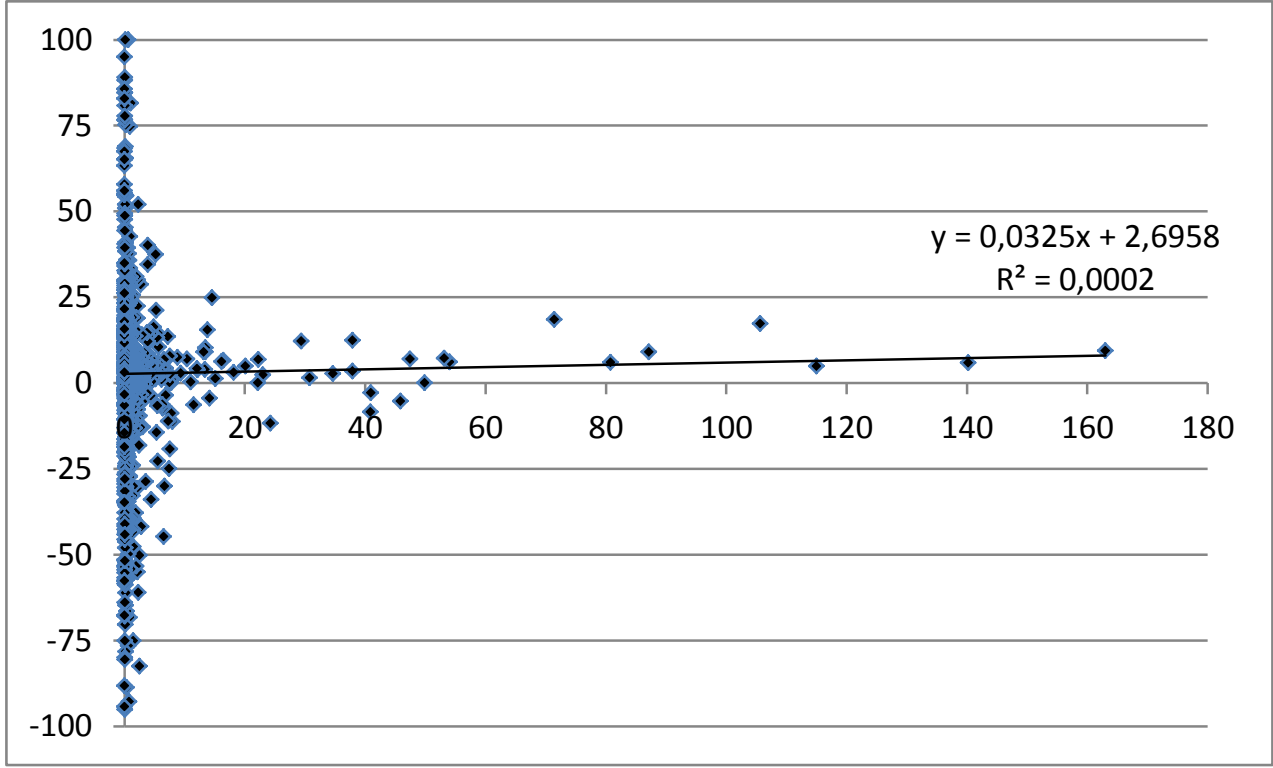

